Article

\title{
Implementation of Integrated Management Systems and Corporate Social Responsibility Initiatives-A Romanian Hospitality Industry Perspective
}

\author{
George H. Ionescu ${ }^{1, *(\mathbb{D}}$, Daniela Firoiu ${ }^{2}$, Ramona Pîrvu ${ }^{3}$, Roxana Bădîrcea ${ }^{4}$ \\ and Cristian Drăgan ${ }^{3}$ \\ 1 Department of Finance, Credit and Accounting, Romanian-American University, Bucharest 012101, Romania \\ 2 Department of Commerce, Economic Integration and Business Administration, Romanian-American \\ University, Bucharest 012101, Romania; firoiu.daniela@profesor.rau.ro \\ 3 Department of Economics, Accounting and International Business, University of Craiova, \\ Craiova 200585, Romania; ramopirvu@gmail.com (R.P.); cdragano11@gmail.com (C.D.) \\ 4 Department of Finance, Banking and Financial Analysis, University of Craiova, Craiova 200585, Romania; \\ roxanamariapirvu@yahoo.com \\ * Correspondence: george.ionescu@profesor.rau.ro; Tel.: +40-7-4475-4752
}

Received: 26 September 2018; Accepted: 12 October 2018; Published: 15 October 2018

check for updates

\begin{abstract}
The growing market value of a company remains the main concern of the management, as well as of the shareholders. Implementing integrated management systems is not always easy and is not low-priced either, but the benefits to clients, management, employees, or shareholders are considerable. At the same time, the involvement of companies in corporate social responsibility activities represents a return of part of the benefits to the community, the benefits being found on multiple plans for all the stakeholders. Through this study, we aim to identify the effects of implementing integrated management systems and quantify the influence of corporate social responsibility initiatives on the market value of hospitality industry companies in Romania. Analyzing the results of the study demonstrates the existence of a direct correlation between the implementation of integrated management systems and the evolution of the economic performance of the companies. Also, the results reveal a positive correlation between the existence of corporate social responsibility initiatives and the increase of the market value of Romanian hotel industry companies.
\end{abstract}

Keywords: hospitality industry; integrated management system; market value; sustainable hospitality; social responsibility

\section{Introduction}

The hospitality industry is considered to be the world's fastest growing sector, having a very high impact on local, national, and global economies. Tourism is chosen as a sector of interest because it plays a substantial direct or indirect role in most national economies, and its significance is widely recognized by all stakeholders. In the last four years, the volume of international tourism activity has grown at a faster rate than global commodity trade, reaching a total value of exports from the tourism industry of USD 1.4 trillion (which represents about $30 \%$ of the value total of services exported); also, the share of the tourism industry in the total volume of exports of goods and services has increased from $6 \%$ to $7 \%$ in 2016 [1].

At the same time, tourism's contribution to GDP growth in Romania is only $2.7 \%$ in 2017, but it is considered an important factor of economic, social, and cultural development by the competent institutions. The Romanian tourism industry needs to adapt to the four fundamental values related to 
economic, social, environmental, and cultural aspects, to practice real pricing, transparency, creativity, ethical behavior, to create value, and be responsible.

Through the influence of external and internal factors on companies, the importance of management systems and standards has increased at an accelerated pace, requiring the adoption of those new systems and standards to ensure that performance is maintained at a high level.

The proliferation of integrated standards points out to what extent businesses now strive to improve the effectiveness and efficiency of the implemented management systems. Further evidence is a relative stabilization in the number of certifications being sought in according to the standards of the International Organization for Standardization (ISO), with particular reference to ISO 9001 for quality management systems (QMS) and ISO 14001 for environmental management systems (EMS). According to the latest ISO survey [2], in 2015, 1,519,952 certificates were issued, which represents an increase of $3 \%$ compared to 2014.

There were a series of empirical studies where a correlation was identified between quality management and company performance [3,4]. Some previous studies have found that the ISO 9001 certification may have a positive impact on companies' economic outcomes [5,6], while other papers have shown that the ISO 9001 certification is not a guarantee for outperforming other companies [7-9].

A few empirical works have carried out the implementation of quality practices and environmental practices together, but we have not found research that has tackled the integrated management systems and corporate social responsibility simultaneously and the impact on market value, and our paper fills this gap.

Most of the studies have mainly focused on developed countries (Spain, U.K., USA, and France), and authors of an analytical review consider it necessary that future studies concentrate on developing and emerging countries [10]. In order to cover this gap, we focused our research on Romanian companies in the hospitality industry.

This paper is organized as follows: in the first part, a literature review is presented regarding the integrated management systems and the relevance for the hospitality industry. Next, the research methodology is described. Then, the results of our study are explained and discussed, and, finally, we present a conclusion section, including some of the implications for hospitality industry companies, as well as the limitations of this study, and we suggest future research directions.

\section{Literature Review}

In order to provide an effective response to requests from the external or internal environment, companies are seeking to implement specialized management systems (such as environment, social responsibility, quality, or health and safety). However, implementing and maintaining functionality of such individual systems proves to be quite costly for the company, which leads to a reduction in the long-term profitability rate. Thus, the more independent management systems that exist, the more justified is their reunification into a single system to ease their use, to increase efficiency, and to remove existing redundancies [11].

Starting from the analysis of the existing needs within the organization, through the hierarchical structuring of the individual management processes, a unitary approach can be achieved through an integrated management system. As a result, such an approach generates unitary structures and processes that are reflected across the entire company, leading to an increase in the efficiency of using available resources such as increasing the chances of meeting current goals [12].

By adopting integrated management systems at the company level, it can be a beneficial transformation at all levels of action (strategic, tactical, and operational). Strategically, the advantage of using integrated management systems provides a reliable interaction mechanism with all stakeholders. From the tactical point of view, following the integration process, a series of internally correlated procedures and processes are developed and implemented, leading to more judicious use of available resources and better control over all business processes [13]. Finally, an increase in the efficiency of the activities carried out (especially in support activities) can be noticed at the operational level, 
which together with a more judicious use of the available resources, leads to an increase in the chances of achieving sustainable growth of a company [14].

The benefits of integration are undeniable, but, the same as with any system or procedure, organizations can also meet obstacles during the implementation of such a system; the most common can be listed as follows: difficulties in obtaining relevant expertise to cover all system requirements; inadequate allocation of resources to the system, which leads to achieving costs higher than the obtained benefits; misalignment between internal and external interests in the company in terms of environmental protection versus increasing the quality of products and services [14].

The implementation process of an integrated management system can prove to be costly, especially for small organizations, but also for new organizations, given the fact that the return on such an investment can be quite long, usually about 14 months [15]. This process is different from organization to organization, being influenced by characteristics such as the type and size of the organization, the nature and complexity of activities, and the types of products or services.

As a result of the integration of management systems, a large number of systems and processes are replaced by a single system, thus significantly facilitating the understanding, implementation, and efficient use by employees. In the opinion of some authors, these integration processes are based on a number of different conditionalities than common ones, like the costs involved, the level of expertise, or the resources available. Making the connection with the investigated directions (quality, environment, safety), these different factors include, for example, the degree of development of the company, the link between environmental issues, and the key internal processes of the company, but also the unique approach on quality and environmental issues [16]. Moreover, over time, it has been shown that operating quality and environmental systems as distinct systems prove to be redundant, and therefore, the solution for increasing the operational efficiency of the organization is the integration of these systems [17].

Liability regarding quality, the environment, and health and safety at work becomes an increasingly important issue for any company's image, which is translated through having certified management systems covering all three spheres. Currently, among the most important standardized management systems are the ISO standards for quality management (ISO 9001) and environmental management (ISO 14001) that are adjusted to work together. The trend is that with each new version of one of the two standards, the two will become more similar. In addition, the standards regarding occupational health and safety management systems (OHSAS 18001, ISO 45001) are also constructed to be successfully used with the first two, which makes the eventual integration of the three in one single system to be increasingly easier [18].

The integration of the main three standard pillars of any organization (quality, environment, and safety) becomes a real necessity in an increasingly globalized society. In addition, given the characteristics and structure of each of the three systems, it should be noted that the application of an integrated management system is always easier for organizations that have already implemented a quality management system because the environmental management system and the occupational health and safety management system can use the structure created earlier for this as a starting point.

In general, most companies place great emphasis on ISO certifications as a marketing tool. There are a number of studies that confirm the benefits of ISO certification, but others fail to identify a strong correlation between ISO certification and the market value of companies or their level of performance.

Regarding the benefits of the quality certifications, Canadases and Karapetrovic [19] have identified different aspects regarding financial and operation results, customer results, and people results. Similarly, Sharma [6] demonstrates that very often, ISO 9000 certification is correlated with an increase of financial performance (earnings per share, profits, or sales per share), mainly due to improvement of internal business processes.

From the second category, of studies that fail to identify a positive correlation between ISO certification and companies' market value, Singels et al. [7] found that ISO 9000 certification for 
companies is not a predictor for surpassing, in terms of economic performances, those companies without such a certification. In a different paper, Rahman [20] found the impact of quality management on organizational performance is not significantly impacted by the existence of ISO 9000 certification. Renuka and Venkateshwara [21] explained that ISO 9000-certified companies adopt advanced technology easier and are more open to use large-scale information technology, compared with non-certified firms.

In the hospitality industry, Ayuso [22] considered that voluntary management systems could have the potential to drive companies to a more sustainable development and help make hotels more competitive. Some similar studies revealed significant differences regarding the economic performance of ISO-certified and uncertified hotels [23,24].

Dos Santos [25] suggests that hotel businesses need to include sustainable practices in their management and operating strategies, taking into consideration the interests of employees, customers, suppliers, and so on.

Regarding corporate social responsibility (CSR), according to ISO 26000, it is defined as "the responsibility of an organization for the impacts of its decisions on society and the environment, through transparent and ethical behavior, that contributes to a sustainable development and integrates expectations of the stakeholders" [26]. The concept of corporate social responsibility covers many aspects related to environment, community, employee rights, recycling, greenhouse gas emissions, and waste reduction. The CSR considers social benefits above the company's interest, stressing that companies should not only pursue their own economic interests but also support the larger interests of the society [27].

Building on the perspective of stakeholder theory, investing in CSR activities can improve the relationship between firms and stakeholders and help businesses secure critical stakeholder-controlled resources. [28].

There are several studies regarding the relationship between CRS and a company's market value, with different results. In the first category of studies, showing a positive correlation between CSR and market value, we can include Soloman and Hansen [29], Fombrun and Shanley [30], or Singh, Sethuraman, and Lam [31]. In the second category, among studies with negative findings, we can include Aupperle et al. [32] and McGuire et al. [33]. The third category of studies, with more nuanced results about the link between CSR and market value, include the research of Margolis and Walsh [34], Xueming and Bhattacharya [35], and Battaglia et. al [36]. At the same time, CSR tourism research is considered at an early stage compared to other areas (Coles et al., 2013) [37] and is at a critical moment.

There is still a research gap regarding the correlation between the implementation of integrated management systems, corporate social responsibility, and companies' value. From this line of study, we conducted qualitative research into the Romanian hospitality industry sector. The sample of the research was represented by companies from the hospitality industry with different exploitation forms, different comfort categories, different sizes, and have implemented integrated quality, environmental, and safety management systems. We consider the following hypotheses:

Hypothesis 1. The implementation of integrated management systems contributes to the increase of the turnover, respectively to the increase of the market value, for the companies in the Romanian hospitality industry.

Hypothesis 2. Investments for CSR activities contribute to the increase of the turnover, respectively to the increase of the market value, for the companies in the Romanian hospitality industry.

Taking into account the diversity of the results of the previous research, we want this study to contribute to the development of knowledge through the analysis made at the level of the companies in the Romanian hotel industry, as well as provide managers with the knowledge and tools needed to make the best decisions. 


\section{Materials and Methods}

To research the relation between the implementation of integrated quality standards, corporate social responsibility, and market value of companies in the Romanian hospitality industry, we produced and distributed a nationwide questionnaire to the companies' management staff, between October 2016-January 2017. The survey sought to capture the changes that occurred on the selected variables, from the point of view of the respondents, after implementing quality standards, compared to the previous period. Based on this survey, we could identify different levels of correlation for the selected factors.

The empirical data were collected from the answers given by representatives of 147 Romanian hotels, from a total population of 1530 two-to-five-star individual hotels, through a structured questionnaire with closed questions and matrix questions. From the total number of completed questionnaires, we selected a number of 130 questionnaires corresponding to the hotels that responded they are certified for at least one ISO standard, which represented $88.43 \%$ of hotels surveyed.

Of the 130 hotels selected nationwide to carry out this research, $60.77 \%$ were independent hotels and $39.23 \%$ were part of a national or international hotel chain. In terms of the size of hotels, $22.31 \%$ had under 25 rooms, $43.31 \%$ had between 25 and 99 rooms, 32.31\% had between 100 and 299 rooms, and $2.07 \%$ had more than 300 rooms. Regarding the hotels' classifications, $13.85 \%$ were rated as two stars, $35.38 \%$ were rated as three stars, $38.46 \%$ were rated as four stars, and $12.31 \%$ were rated as five stars (Figure 1).

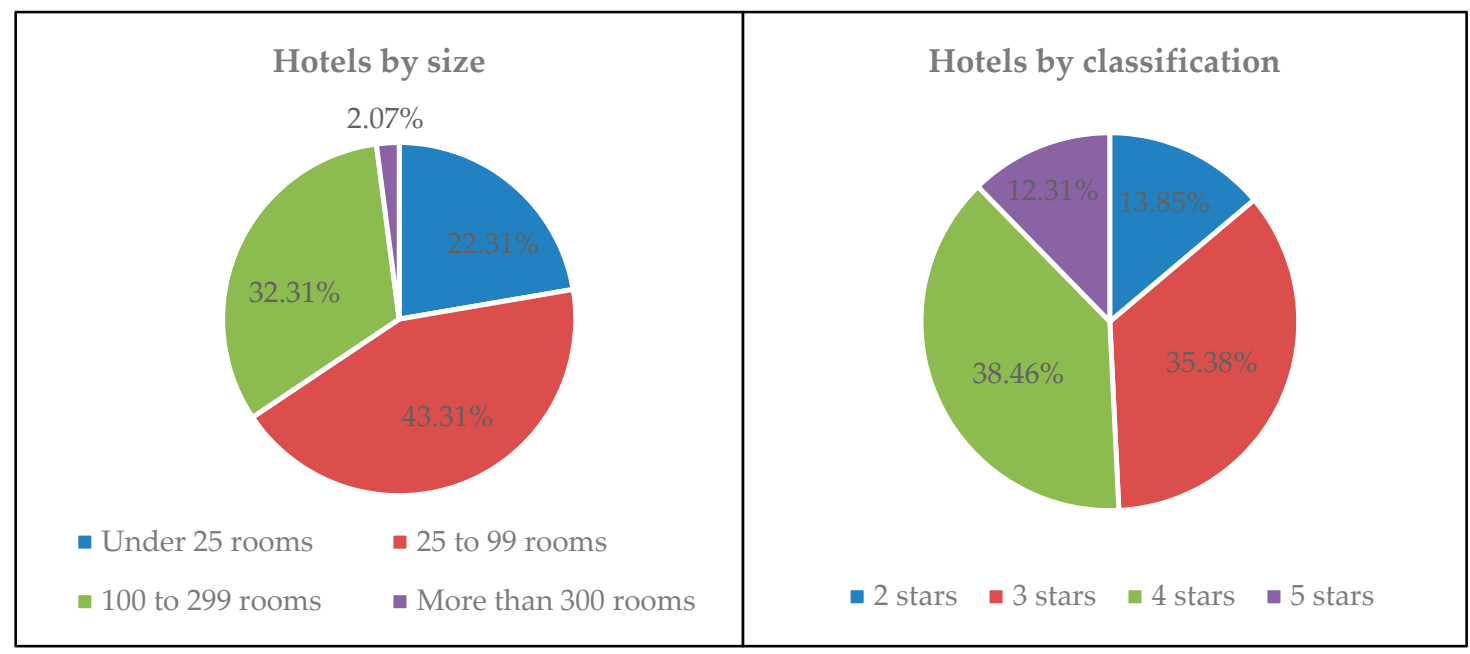

Figure 1. Data breakdown for the selected hotels included in the study.

For the conducted analysis, the turnover $(T)$ was chosen as the dependent variable and the following independent variables-the investment in human resource development (IHR), the investment in information technology and communications (ITC), the investment in hotel infrastructure $(I H I)$, the expenses assigned for marketing activity $(E M K)$, the expenses assigned for social responsibility activities (ESR), the employee perception of organizational culture (POC), and the time allotted for customer complaints management (CCM)-have been chosen as predictors. All the selected variables were evaluated by the respondents through closed ended questions. For each analyzed variable, a conversion of the value judgments into numeric expressions is required, based on a five-point Likert scale, as follows: 5 meaning "has increased a lot"; 4 meaning "has increased a little"; 3 meaning "has not changed at all/do not know"; 2 meaning "has dropped a little"; 1 meaning "has decreased a lot".

In order to determine the minimum number of respondents ( $N$-sample size), two ways have been considered. First one, presented by Popa [38], of which, quoting Tabachnick and Fidell [39], refers to determine $N=50+8{ }^{*} I V N$, where $I V N$ is the number of independent variables. The second 
method recommends a minimum ratio of 15 to 1 between the number of respondents and the number of independent variables. For our research, the number of independent variables is seven, so a sample of $N=130$ respondents was set, providing a 18.57 respondents to independent variables ratio.

These key factors were selected from the answers received from the hotels, which were certified for quality, environmental, and/or safety systems standards, and were based on the most relevant changes/implications at unit level after implementing these standards with all the benefits and constraints involved.

The main characteristics of the key factors considered in the analysis are presented in Table 1.

Table 1. Main characteristics of analyzed variables.

\begin{tabular}{cccccc}
\hline Variable & Variable Type & Mean & Standard Deviation & $\boldsymbol{N}$ & Variation Coefficient \\
\hline T & Dependent & 4.1769 & 0.8933 & 130 & 21.3856 \\
IHR & Independent & 1.9923 & 1.3029 & 130 & 65.3978 \\
ITC & Independent & 3.6154 & 0.8838 & 130 & 24.4464 \\
IHI & Independent & 3.8692 & 0.9913 & 130 & 25.6213 \\
$E M K$ & Independent & 3.5000 & 0.8093 & 130 & 23.1241 \\
$E S R$ & Independent & 2.9615 & 0.6024 & 130 & 20.3398 \\
POC & Independent & 2.8923 & 0.6379 & 130 & 22.0551 \\
CCM & Independent & 4.4385 & 0.9065 & 130 & 20.4240 \\
\hline
\end{tabular}

Source: own construction by using SPSS.

Unlike the other variables, the $I H R$ variable had a very high standard deviation (1.3029) resulting in a variation coefficient of $65.39 \%$ and, consequently, its mean value (1.9923) was not statistically significant. For all the other variables, variation coefficients were significantly less than $35 \%$, therefore their mean values were considered representative.

\section{Results}

To identify functional links between the dependent variable $T$ (Turnover) and the seven predictors, the diagonal matrix $B$ and the predictors vector (independent variables-VI) have been composed:

$$
B=\left(\begin{array}{cccc}
b_{1} & 0 & \ldots & 0 \\
0 & b_{2} & \ldots & 0 \\
\ldots & \ldots & \ldots & \ldots \\
0 & 0 & \ldots & b_{k}
\end{array}\right) V I=(\text { IHR ITC IHI EMK ERS POC CSI })
$$

Taking these into account, Model_1 will have the following form:

$$
\text { Model_1: } T=a+B * V I^{T}+\varepsilon, \quad a \in R, B \in M_{7 \times 7} \text { and } \varepsilon \sim N\left(0, \sigma_{\varepsilon}^{2}\right)
$$

Data presented in Table 2 shows that Model_1 outlined a fairly large influence of the predictors' values on the turnover of the hotels that have taken measures to implement integrated quality, environmental, and safety management systems. First, information in this regard was provided by the multiple correlation coefficient's value $(R=0.846)$, which shows that between the result variable $T$ and the predictors $\left(V I_{k}\right)$, there was a high intensity correlation. Furthermore, the value of the R_Square $\left(R^{2}\right)$ determination coefficient exposed that the variation of the $T$ variable was determined with $71.5 \%$ by the combined variability of the independent variables.

At the same time, the result of putting into practice the ANOVA methodology demonstrated that Model_1 was statistically significant, which means that the regressors' influence was greater than the residues' influence. The conclusion starts from the fact that the calculated value of the F-statistic (43.809) was higher than the critical value $\mathrm{F}_{0.05 ; 7 ; 122}=1.94$, and Sig. $=0.000<\alpha=0.05$. 
The values shown in Table 2, as well as the above findings, only relate to Model_1 as a whole. In order to validate or invalidate the model structure, it was necessary to analyze the statistical significance of the values of predictors' $\left(V I_{k}\right)$ coefficients $\left(b_{k}\right)$. Their features are shown in Table 3.

Table 2. Model summary and ANOVA for Model_1.

\begin{tabular}{|c|c|c|c|c|c|}
\hline \multicolumn{6}{|c|}{ Model Summary } \\
\hline$R$ & R_Square & Adjusted R_Square & Std. Error of the Estimate & \multirow{2}{*}{\multicolumn{2}{|c|}{$\begin{array}{c}\text { Durbin-Watson } \\
1.812\end{array}$}} \\
\hline $0.846^{*}$ & 0.715 & 0.699 & 0.49002 & & \\
\hline \multicolumn{6}{|c|}{ ANOVA } \\
\hline & Sum of Squares & df & Mean Square & $\mathrm{F}$ & Sig. \\
\hline Regression & 73.636 & 7 & 10.519 & 43.809 & 0.000 * \\
\hline Residual & 29.295 & 122 & 0.240 & & \\
\hline Total & 102.931 & 129 & & & \\
\hline
\end{tabular}

* Predictors (const.): IHR, ITC, IHI, EMK, ESR, POC, CCM. Source: own construction by using SPSS.

Table 3. Characteristics of Model_1 coefficients.

\begin{tabular}{|c|c|c|c|c|c|c|c|}
\hline \multirow[t]{2}{*}{ Variable } & \multicolumn{2}{|c|}{$\begin{array}{l}\text { Unstandardized } \\
\text { Coefficients }\end{array}$} & \multirow{2}{*}{$\begin{array}{c}\begin{array}{c}\text { Standardized } \\
\text { Coefficients }\end{array} \\
\beta\end{array}$} & \multirow[t]{2}{*}{$\mathbf{t}$} & \multirow[t]{2}{*}{ Sig. } & \multicolumn{2}{|c|}{$95 \%$ Confidence Interval for $B$} \\
\hline & $B$ & Std. Error & & & & Lower Bound & Upper Bound \\
\hline$a$ (const.) & 0.034 & 0.259 & & 0.133 & 0.895 & -0.478 & 0.546 \\
\hline$I H R$ & 0.010 & 0.034 & 0.014 & 0.283 & 0.778 & -0.058 & 0.077 \\
\hline ITC & 0.408 & 0.059 & 0.404 & 6.965 & 0.000 & 0.292 & 0.524 \\
\hline IHI & 0.181 & 0.061 & 0.201 & 2.983 & 0.003 & 0.061 & 0.301 \\
\hline$E M K$ & 0.233 & 0.078 & 0.211 & 2.994 & 0.003 & 0.079 & 0.387 \\
\hline ESR & 0.249 & 0.101 & 0.168 & 2.470 & 0.015 & 0.049 & 0.448 \\
\hline POC & -0.165 & 0.096 & -0.118 & -1.721 & 0.088 & -0.355 & 0.025 \\
\hline CCM & 0.197 & 0.072 & 0.200 & 2.748 & 0.007 & 0.055 & 0.339 \\
\hline
\end{tabular}

Source: own construction by using SPSS.

From the seven coefficients of Model_1, only five have values significantly different from zero. As for the $I H R$ variable coefficient Sig. $=0.778>\alpha=0.05$, and for the POC variable coefficient Sig. $=0.088>\alpha=0.05$, it results that the null hypothesis was accepted and, therefore, these were not statistically significant and should be removed from the model. The same conclusion was reached by analyzing the $95 \%$ confidence interval, which for both variables have different signs ( 0 value lies within the interval).

The new model, Model_2, differed from Model_1 only in the size of the diagonal matrix $B$ and the structure of the vector $V I$ :

$$
\begin{gathered}
\text { Model_2: } T=a+B * V I^{T}+\varepsilon, \quad a \in R \text { and } \varepsilon \sim N\left(0, \sigma_{\varepsilon}^{2}\right) \\
\text { where } B \in M_{5 \times 5} ; V I=(I T C \text { IHI EMK ESR CSI })
\end{gathered}
$$

The main parameters, as well as the results of applying the ANOVA methodology for Model_2 as a whole, are presented in Table 4.

A first conclusion to be drawn was that in Model_2, between the result variable $T$ and the predictors $\left(V I_{k}\right)$, there was a high-intensity correlation, the value of the multiple correlation coefficient $(R)$ being 0.846 . Also, the value of R_Square pointed out that the variation of the turnover $(T)$ was determined by $70.8 \%$ of the combined variability of independent variables.

Regarding the statistical significance of Model_2 for a 95\% confidence level, given that both the calculated value of the F-statistic $=60.809$ was significantly higher than the critical value $\mathrm{F}_{0.05 ; 5 ; 122}=2.21$, and the value of Sig. $=0.000<\alpha=0.05$, then the null hypothesis was rejected and the alternative hypothesis was accepted. As a consequence, Model_2 proved to be valid and statistically significant for the chosen significance level. 
Table 4. Model summary and ANOVA for Model_2.

\begin{tabular}{|c|c|c|c|c|c|}
\hline \multicolumn{6}{|c|}{ Model Summary } \\
\hline$R$ & R_Square & Adjusted R_Square & Std. Error of the Estimate & \multirow{2}{*}{\multicolumn{2}{|c|}{$\begin{array}{c}\text { Durbin-Watson } \\
1.809\end{array}$}} \\
\hline $0.842 *$ & 0.708 & 0.697 & 0.49201 & & \\
\hline \multicolumn{6}{|c|}{ ANOVA } \\
\hline & Sum of Squares & $\mathrm{df}$ & Mean Square & F & Sig. \\
\hline Regression & 72.914 & 5 & 14.583 & 60.241 & 0.000 * \\
\hline Residual & 30.017 & 124 & 0.242 & & \\
\hline Total & 102.931 & 129 & & & \\
\hline
\end{tabular}

On the other hand, as shown in Table 5 , all five $b_{k}$ coefficients corresponding to the predictors were statistically significant (significantly different from zero). This conclusion resulted from the fact that all values of the $t$-statistic (Student test) belonged to the critical region, $t>t_{0.025} ; 130=1.979$, as well as from the fact that Sig. $<\alpha=0.05$. Regarding constant $a$, its value was not significantly different from 0 (Sig. $=0.942>\alpha=0.05$ ), but, in the case of this analysis, the value of $<a>$ had no practical significance. In conclusion, Model_2 was also structurally valid (statistically significant), with the predictors' coefficients, for the chosen significance level, taking values within the confidence range limits (Table 5) corresponding to each one.

Table 5. Characteristics of Model_2 coefficients

\begin{tabular}{|c|c|c|c|c|c|c|c|}
\hline \multirow[t]{2}{*}{ Variable } & \multicolumn{2}{|c|}{$\begin{array}{l}\text { Unstandardized } \\
\text { Coefficients }\end{array}$} & \multirow{2}{*}{$\begin{array}{c}\begin{array}{c}\text { Standardized } \\
\text { Coefficients }\end{array} \\
\beta\end{array}$} & \multirow[t]{2}{*}{$\mathbf{t}$} & \multirow[t]{2}{*}{ Sig. } & \multicolumn{2}{|c|}{$95 \%$ Confidence Interval for $B$} \\
\hline & $B$ & Std. Error & & & & Lower Bound & Upper Bound \\
\hline$a$ (const.) & -0.019 & 0.256 & & -0.073 & 0.942 & -0.525 & 0.488 \\
\hline ITC & 0.404 & 0.058 & 0.400 & 6.959 & 0.000 & 0.289 & 0.519 \\
\hline IHI & 0.189 & 0.061 & 0.210 & 3.117 & 0.002 & 0.069 & 0.309 \\
\hline$E M K$ & 0.185 & 0.073 & 0.168 & 2.537 & 0.012 & 0.041 & 0.330 \\
\hline$E S R$ & 0.190 & 0.095 & 0.128 & 2.014 & 0.046 & 0.003 & 0.378 \\
\hline CCM & 0.178 & 0.071 & 0.181 & 2.505 & 0.014 & 0.037 & 0.319 \\
\hline
\end{tabular}

Given the fact that the least squares method had been used for determining the values of the $b_{k}$ predictors' coefficients, the existence of influential cases and extreme cases had been verified, as well as the multicollinearity and independence (no autocorrelation) of residues $(\varepsilon)$ hypotheses.

Extreme cases could affect the stability of Model_2's regression equation. The existence of extreme cases was signaled by the minimum values of std. residual and stud. residual (Table 6), which should also be within the $[-2.0,2.0]$ range. Table 6 shows that there were both positive and negative values outside this interval. The minimum values $(-2.404$ and, respectively, -2.446$)$ corresponded to respondent 1 and the maximum values corresponded to respondents 35, 94, 106, and 130; in total, five extreme cases that do not belong to the $[-2.0,2.0]$ range, but were included in the $[-3.0,3.0]$ range. Taking into consideration the fact that their share in the respondents' total was $3.85 \%<5.0 \%$, the hypothesis stating that the regression equation corresponding to Model_2 was stable was accepted.

In order to verify the existence of some influential cases that may affect the values of the $b_{k}$ regression coefficients [40], Cook's distance values were checked. Since all 130 values of Cook's distance were much smaller than 1 , it was clear that there were no influential cases within the sample and, therefore, the values of the $b_{k}$ coefficients were not influenced by these.

Checking the residues' $(\varepsilon)$ independence was performed by applying the Durbin-Watson test (Table 4). Given that the analyzed sample contained $N=130$ elements, and the number of predictors was five, the Durbin-Watson distribution table for $\alpha=0.05$ shows the value $d_{U}=1.77743$ [41]. 
Since DW $=1.809 \in\left(\mathrm{d}_{\mathrm{U}}=1.77743,4-\mathrm{d}_{\mathrm{U}}=2.22257\right)$, the null hypothesis was accepted: residues

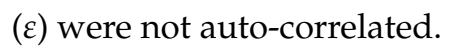

Table 6. Residuals statistics.

\begin{tabular}{cccccc}
\hline & Minimum & Maximum & Mean & Std. Deviation & $\boldsymbol{N}$ \\
\hline Residual & -1.18264 & 1.03584 & 0.000 & 0.482 & 130 \\
Std. Residual & -2.404 & 2.105 & 0.000 & 0.980 & 130 \\
Stud. Residual & -2.446 & 2.154 & -0.004 & 1.004 & 130 \\
Cook's & 0.000 & 0.070 & 0.008 & 0.014 & 130 \\
Distance & & & & \\
\hline
\end{tabular}

Source: own construction by using SPSS.

For checking the collinearity, the specific data have been analyzed (Table 7). The collinearity avoidance condition was that the Tolerance values corresponding to the five predictors to be greater than (1-Adjusted R_Square). In the case of Model_2, in Table 4, the value of Adjusted R_Square is 0.697. Taking this into account, the collinearity avoidance condition was satisfied because all Tolerance values (Table 7) were higher than 0.303 . The same conclusion was drawn by taking into account the VIF (variation inflation factor) values, VIF $=1$ / Tolerance.

Table 7. Standardized coefficients, correlations, and collinearity statistics for Model_2.

\begin{tabular}{ccccccc}
\hline \multirow{2}{*}{ Variables } & Standardized Coefficients & \multicolumn{3}{c}{ Correlations } & \multicolumn{3}{c}{ Collinearity Statistics } \\
\cline { 2 - 7 } & $\boldsymbol{\beta}$ & Zero-Order & Partial & Part & Tolerance & VIF \\
\hline ITC & 0.400 & 0.686 & 0.530 & 0.337 & 0.713 & 1.402 \\
$I H I$ & 0.210 & 0.648 & 0.270 & 0.151 & 0.519 & 1.925 \\
$E M K$ & 0.168 & 0.595 & 0.222 & 0.123 & 0.536 & 1.864 \\
$E S R$ & 0.128 & 0.589 & 0.178 & 0.098 & 0.578 & 1.729 \\
$C C M$ & 0.181 & 0.679 & 0.219 & 0.121 & 0.451 & 2.215 \\
\hline \multicolumn{5}{c}{ Source: own construction by using SPSS. }
\end{tabular}

The final conclusion was that Model_2 qualified for being used in the analysis of the predictors' (investment in IT\&C, investment in hotel infrastructure, assigned expenses for marketing activities, assigned expenses for social responsibility activities, and time allotted for customer complaints management) influence on $T$.

In Table 7, Correlations Zero-Order are the Pearson correlation coefficients from among each of the five predictors (independent variables) and the turnover (dependent variable), and the Partial values and the Part values of predictors represent the values of the partial $\left(\mathrm{r}_{\mathrm{p}}\right)$ and semi partial $\left(\mathrm{r}_{\mathrm{sp}}\right)$ correlation (between them and the turnover) coefficients.

The Pearson correlation coefficients highlight links of direct and medium intensity between the predictors and the turnover, the most significant one being that with the investment in IT\&C, and the lowest being that with the assigned expenses for social responsibility activities. Also, information regarding the influence of predictors on the turnover was evidenced by the values of the Standardized Coefficients that confirm the above mentioned.

The most conclusive information regarding the influence of each predictor on the turnover was obtained by taking into account the $\mathrm{r}_{\mathrm{sp}}$ values that allowed the definition of determination coefficients corresponding to each predictor $\left(\mathrm{r}_{\mathrm{sp}}{ }^{2}\right)$. These highlighted the fact that the investment in IT\&C had the biggest influence on the turnover, with $11.39 \%$ of the variation of the turnover variable being due to the attention given to IT\&C investment.

For the other predictors, the variation of the turnover could be explained in much lower proportions: $2.29 \%$ by investment in hotel infrastructure, $1.52 \%$ by expenses assigned for marketing activities, $1.48 \%$ by time allotted for customer complaints management, and only $0.95 \%$ by expenses 
assigned for social responsibility activities. It should be noted that, as a whole, due to the synergistic effect, the five predictors influenced the turnover by $70.8 \%$ (Table 4 ).

\section{Discussion}

The most common reasons [7] for implementing a quality management system is the willingness to invest for building a quality culture at company level. This quality culture can be based on costs and deficiencies reduction, and/or products or services improvement. On the other hand, an effective implemented quality culture will lead to an improved ability of the company to adapt to the market conditions and customers' requirements, better services, and finally, a good corporate image.

Quality management systems and quality culture can influence financial and economic performance of a company in two complementary ways. It can have internal impacts through the processes and external impacts through the market. The effects of internal factors over performance are directly related to costs reduction, productivity increases, waste minimization, less time used to correct deficiencies, and a high degree of employee satisfaction at the workplace. External factors impacting over performance have to do mainly with the customer satisfaction and a good overall image of the company, which are some of the most important attributes in the hospitality industry.

Of course, all these benefits are accompanied by a series of additional costs incurred by the implementation and certification of quality, environmental, and safety systems standards. As resulted from the conducted research, the most important costs were related to the harmonization of the IT infrastructure to the requirements of the quality standards, allotted working time to obtain the quality certification, increase of the bureaucracy, and reduced investments in human resource development.

From the total sample of 130 selected hotels, 100\% of them reported ISO 9001 implementation, $90.0 \%$ reported ISO 14001 implementation, 67.69\% reported ISO 18001 implementation, and 57.69\% reported the implementation of an integrated quality, environmental, and safety management system.

In terms of the effects of implementing at least one management system standard over turnover of surveyed companies, the overall result was that the implementation costs had a positive influence (Table 8). The most important finding was that after the implementation of an integrated management system, the turnover (thus, as effect, the market value of the company) increased a little for $38.67 \%$ of the hotels or increased a lot for $4 \%$ of the hotels, which meant an overall increase for $42.67 \%$ of the cases.

Table 8. Turnover change after implementing at least one management system standard.

\begin{tabular}{cccccc}
\hline & Dropped a Little & No Change & Increased a Little & Increased a Lot & $N$ \\
\hline ISO 9001 & $5.38 \%$ & $55.39 \%$ & $29.23 \%$ & $10.00 \%$ & 130 \\
ISO 14001 & $8.55 \%$ & $68.38 \%$ & $22.22 \%$ & $0.85 \%$ & 117 \\
ISO 18001 & $6.82 \%$ & $75.00 \%$ & $13.64 \%$ & - & 88 \\
IMS & - & $57.33 \%$ & $38.67 \%$ & $4.00 \%$ & 75 \\
\hline
\end{tabular}

Source: own construction by using SPSS.

The findings of this study suggest that the main advantage of implementing an integrated quality, environmental, and safety management system could be the necessity to support this action with an integrated IT system.

The positive influence of IT\&C investment over turnover of companies is consistent with the survey results of Mithas et al. [42], which found that investment in IT had a greater impact on the company's profits than comparable spending on either advertising or R\&D, and IT investments were more effective in improving profitability by increasing revenue than by decreasing operating expenses, especially supporting sales growth through increasing customer satisfaction and customer retention ratios.

On the other hand, this finding of the research can be explained by the fact that the implementation of IT systems has, besides the direct influence, some indirect influence, with significant impact on 
the performance of the company. These indirect influences have to do with an increase in marketing and promotion activity and improved on-line presence, which lead to higher sales volumes. Thus, the relevant influence of the investment in IT\&C over turnover and, in general, on market value of the company, could be explained by the aggregate influence of the constituent direct and indirect factors.

The relatively low influence of the investments in hotel infrastructure could be explained by the fact that the level of these investments are, in general, quite high and requires a large amount of financial resources. On the other hand, these kinds of infrastructure investment plans are spread over longer periods of time and, as a regular basis, are made continuously. There are only a limited number of situations when the hotel is entirely closed to allow infrastructure investment to be made.

The findings of this study have shown that we can identify a positive correlation between the implementation of integrated management systems and companies' market value for the Romanian hospitality industry, thus supporting the Hypothesis 1 (The implementation of integrated management systems contributes to the increase of the turnover, respectively to the increase of the market value, for the companies in the Romanian hospitality industry).

Another interesting finding of this study is that investment in corporate social responsibility activities had a positive impact of $0.95 \%$ over the turnover of companies from the hospitality industry in Romania. This influence was much smaller than the influence of the investment in IT\&C, but is consistent with similar studies that identified a positive correlation between CSR and firm performance, with the relationship being somewhat ambiguous $[35,36,43,44]$. The previous studies revealed that customer loyalty could decrease firm risk [45]. The general perception of the hotel managers after starting to invest on a regular basis on CSR activities was that in $10.77 \%$ of the hotels, they could see an increase in turnover, for $5.38 \%$ of the hotels they could see a decrease in turnover, and for the rest of the hotels $(83.85 \%)$, no change was reported.

At the same time, the investment in CSR activities could be an important factor for increasing companies' market value over time because of the long-term investors and their influence over cash-flow risks [46] or over corporate governance by collaborating with other market participants [47].

Exploring the relation between investments for CSR activities and the effects on turnover for the companies in the Romanian hospitality industry (Hypothesis 2), our research has shown mixed results that were unable to validate, but not to invalidate, the hypothesis. These results can be attributed mainly to the low degree of local market development, lack of information and motivation for managers of travel and tourism industry companies, as well as to the low degree of knowledge and involvement of investors and stakeholders.

According to the European Commission, there are two main dimensions of corporate social responsibility, an internal dimension related to internal practices of the company (human resources management, health and safety at work, adaptation to change, and management of environmental impacts and natural resources) and an external dimension involving all stakeholders from outside the company (local communities, business partners, suppliers and consumers) [48].

On the other hand, the degree of involvement of the companies in corporate social responsibility actions is directly related with the degree of economic development of the country. In developing countries (like Romania), corporate social responsibility is most commonly associated with philanthropy or charity, and tends to be less formalized or institutionalized in terms of the CSR benchmarks commonly used in developed countries [49].

Regarding the correlation between the results obtained after the implementation of a management system standard, and especially an integrated management system and the expectations of the hotel managers and overall satisfaction, more than $90 \%$ of respondents said they were satisfied or very satisfied (Table 9).

Taking all these remarks into consideration, it should be noted that the companies operating in the Romanian hospitality industry were aware of the importance which must be granted to the corporate social responsibility actions, considering both internal and external dimensions. At the same 
time, the companies were rewarded through merit recognition by the stakeholders, which led to the increasing of their market value.

Table 9. Results obtained after the implementation of a management system standard.

\begin{tabular}{ccccc}
\hline & Do Not Know & Satisfied & Very Satisfied & $N$ \\
\hline ISO 9001 & $9.23 \%$ & $86.15 \%$ & $4.62 \%$ & 130 \\
ISO 14001 & $0.85 \%$ & $64.96 \%$ & $34.19 \%$ & 117 \\
ISO 18001 & $2.27 \%$ & $73.87 \%$ & $23.86 \%$ & 88 \\
IMS & - & $57.33 \%$ & $42.67 \%$ & 75 \\
\hline \multicolumn{5}{c}{ Source: own construction by using SPSS. }
\end{tabular}

\section{Conclusions}

Starting from the main objective of the conducted study, the identification of correlations between the implementation of integrated management systems, corporate social responsibility, and companies' market value, seven result variables were defined: the level of investment in human resource development, the level of investment in IT\&C, the level of investment in hotel infrastructure, the expenses for marketing activity, the expenses for social responsibility activities, the employee perception of organizational culture, and the time allotted for customer complaints management.

The findings of our study have shown that we can identify a positive correlation between the implementation of integrated management systems and companies' market value for the Romanian hospitality industry. In fact, $42.67 \%$ of the surveyed managers reported a small or moderate increase in turnover after implementing an integrated management system, which confirmed our first hypothesis.

Consequently, we investigated the effect of the seven selected predictors for the evolution of turnover. From the initial model we had to remove two predictors as being statistically non-significant (the level of investment in human resource development and the employee perception of organizational culture). The last five predictors were included in a reviewed model and we could identify the particular influences over turnover, respectively over the market value of the companies, with a $70.8 \%$ synergistic influence. The influence of individual factors varied between $11.39 \%$ (level of investment in IT\&C) and $0.95 \%$ (expenses assigned for social responsibility activities).

These findings are, in general, consistent with different research results that demonstrated that certified organizations assign more importance to quality management, employee training, and information technology $[19,22,50]$, or with another category of studies that identify a positive association between implementation of quality standards and ISO certification and firm performance $[6,50,51]$.

With regard to the second hypothesis, the results of the study showed mixed results that were unable to validate, but not to invalidate, our assumptions. Analyzing the responses of hotel managers following the start of investment in CSR activities, in 10.77\% of the cases, a small increase in turnover may have been due to this factor.

These results are consistent with some of the existing studies. It is well known that social responsibility should be relevant for tourism companies because of its positive impact on their own reputation, and also on the satisfaction degree of clients and employees [52], but are mainly directed towards environmental conservation [53]. Tourism firms with constant corporate social responsibility actions add new values to the business activities, which will lead to a higher competitiveness and a sustainable business model [54]. Despite the benefits for both tourism companies and tourism destinations, only $2 \%$ of tourism companies all over the world are implementing corporate social responsibility programs [55].

Regarding the implications of this study for the business environment, it is interesting to note that in the opinion of hotels' management in Romania, the medium and long-term effects of implementing a management system standard, and especially an integrated management system, were undeniable, even though direct causal links could not always be highlighted. The most important result was 
that more than $90 \%$ of managers agreed that implementation has generated had positive results for the company.

We were able to identify a direct link between the investments made for the implementation of an integrated management system and the increase in the turnover and market value of the Romanian hospitality industry companies, which could act as a good incentive for the large-scale adoption of these tools. On the other hand, we could not identify a direct causal relation between investments in CSR activities, which implied the need for additional efforts by all stakeholders to recognize and validate the value of these investments and, implicitly, their reflection in increasing the market value of companies.

This research, being based on a cross-sectional survey research, showed some limitations, especially regarding the evidence on the differences between companies who have implemented integrated quality, environmental, and safety management systems and those that have not implemented such systems, and the influence over companies' market value.

As for the future research directions, we intend to investigate in detail the influence of different ISO certifications over the economic and financial performances of the companies in the hospitality industry, trying to identify a representative model. Also, we intend to expand our research scale to the European and international level to gather more relevant data for the hospitality industry.

Author Contributions: The author G.I. carried out the research and wrote the article. D.F. and R.B. supervised the research proposal and methodology and acted as the research co-coordinators, R.P. and C.D. contributed to the research methodology and proofread the article.

Funding: This research received no external funding.

Conflicts of Interest: The authors declare no conflict of interest.

\section{References}

1. UNWTO. UNWTO Tourism Highlights, 2017 Edition. Available online: www.unwto.org (accessed on 20 February 2018).

2. ISO. The ISO Survey of Management System Standard Certifications 2015. Geneva. 2015. Available online: https:/ / www.iso.org (accessed on 22 February 2018).

3. Easton, G.S.; Jarrell, S.L. The effects of total quality management on corporate performance: An empirical investigation. J. Bus. 1998, 71, 253-307. [CrossRef]

4. Hendricks, K.B.; Singhal, V.R. The long-run stock price performance of firms with effective TQM programs. Manag. Sci. 2001, 47, 359-368. [CrossRef]

5. Wayhan, V.B.; Kirche, E.T.; Khumawala, B.M. ISO 9000 certification: The financial performance implications. Tota. Qual. Manag. 2001, 13, 217-231.

6. Sharma, D.S. The association between ISO 9000 certification and financial performance. Int. J. Account. 2005, 40, 151-172. [CrossRef]

7. Singels, J.; Ruel, G.; van de Water, H. ISO 9000 series certification and performance. Int. J. Qual. Reliab. Manag. 2001, 18, 62-75. [CrossRef]

8. Tsekouras, K.; Dimara, E.; Skuras, D. Adoption of a quality assurance scheme and its effect on firm performance: A study of Greek firms implementing ISO 9000. Total Qual. Manag. 2002, 13, 827-834. [CrossRef]

9. Martinez-Costa, M.; Martinez-Lorente, A.R. A triple analysis of ISO 9000 effects on company performance. Int. J. Prod. Perform. Manag. 2007, 56, 484-499. [CrossRef]

10. Aragon-Correa, J.A.; Martin-Tapia, I.; De la Torre-Ruiz, J.M. Sustainability Issues and Hospitality and Tourism Firms' Strategies: Analytical Review and Future Directions. Int. J. Contemp. Hosp. Manag. 2015, 27, 498-522. [CrossRef]

11. Wilson, R.C. An integrated ISO effort may boost efficiency. Pollut. Eng. 1999, 31, 33.

12. Karapetrovic, S. Musings on integrated management systems. Meas. Bus. Excel. 2003, 7, 4-13. [CrossRef]

13. Asif, M.; Searcy, C.; Zutshi, A.; Ahmad, N. An integrated management systems approach to corporate sustainability. Eur. Bus. Rev. 2011, 23, 353-367. [CrossRef] 
14. Zutshi, A.; Sohal, A.S. Integrated management system: The experiences of three Australian organizations. J. Manuf. Technol. Manag. 2005, 16, 211-232. [CrossRef]

15. Avram, S.E. Implicatiile Implementarii Unui Sistem Integrat de Management Intr-o Organizatie. Simpozionul, Impactul Acquis-Ului Comunitar Asupra Echipamentelor si Tehnologiilor de Mediu, Agigea 2009. Available online: http:/ / www.inginerie-electrica.ro/acqu/pdf/2009_s2_11.pdf (accessed on 5 June 2018).

16. Peris-Ortiz, M.; Álvarez-García, J.; Rueda-Armengot, C. Achieving Competitive Advantage through Quality Management; Springer: Cham, Switzerland, 2015; ISBN 978-3-319-17251-4. [CrossRef]

17. Väyrynen, S.; Häkkinen, K.; Niskanen, T. Integrated Occupational Safety and Health Management: Solutions and Industrial Cases; Springer: Cham, Switzerland, 2015; ISBN 978-3-319-13179-5.

18. Oskarsson, K.; Von Malmborg, F. Integrated Management Systems as a Corporate Response to Sustainable Development. Corp. Soc. Responsib. Environ. Manag. 2005, 12, 121-128. [CrossRef]

19. Casadesus, M.; Karapetrovic, S. Has ISO 9000 lost some of its luster? A longitudinal impact study. Int. J. Oper. Prod. Manag. 2005, 25, 580-596. [CrossRef]

20. Rahman, S. A comparative study of TQM practice and organizational performance of SMEs with and without ISO 9000 certification. Int. J. Qual. Reliab. Manag. 2001, 18, 35-49. [CrossRef]

21. Renuka, S.D.; Venkateshwara, B.A. A comparative study of human resource management practices and advanced technology adoption of SMEs with and without ISO certification. Singap. Manag. Rev. 2006, 28, 41-61.

22. Ayuso, S. Comparing voluntary policy instruments for sustainable tourism: The experience of the Spanish hotel sector. J. Sustain. Tour. 2007, 15, 144-159. [CrossRef]

23. Segarra-Oña, M.; Peiró-Signes, A.; Verma, R. Does Environmental Certification Help the Economic Performance of Hotels? Evidence from the Spanish Hotel Industry. Cornell Hosp. Q. 2012, 53, 242-256. [CrossRef]

24. Molina-Azorín, J.; Tarí, J.J.; Pereira-Moliner, J.; Lopez-Gamero, M.; Pertusa-Ortega, E. The effects of quality and environmental management on competitive advantage: A mixed methods study in the hotel industry. Tour. Manag. 2015, 50, 41-54. [CrossRef]

25. Dos Santos, R.A.; Méxas, M.P.; Meiriño, M.J. Sustainability and hotel business: Criteria for holistic, integrated and participative development. J. Clean. Prod. 2017, 142, 217-224. [CrossRef]

26. International Organization for Standardization, ISO 26000-guidance on SR/CSR for all types of companies nad organizations. Available online: https:/ /iso26000.info (accessed on 14 September 2018).

27. Ghoul, S.E.; Guedhami, O.; Kwok, C.C.Y.; Mishra, D.R. Does corporate social responsibility affect the cost of capital? J. Bank. Finance 2011, 35, 2388-2406. [CrossRef]

28. Lin, C.S.; Chang, R.Y.; Dang, V.T. An Integrated Model to Explain How Corporate Social Responsibility Affects Corporate Financial Performance. Sustainability 2015, 7, 8292-8311. [CrossRef]

29. Soloman, R.; Hansen, K. It's Good Business; Atheneum: New York, NY, USA, 1985.

30. Fombrun, C.; Shanley, M. What's in a Name? Reputation Building and Corporate Strategy. Acad. Manag. J. 1990, 33, 233-258.

31. Singh, P.; Sethuraman, K.; Lam, J. Impact of Corporate Social Responsibility Dimensions on Firm Value: Some Evidence from Hong Kong and China. Sustainability 2017, 9, 1532. [CrossRef]

32. Aupperle, K.; Carroll, A.; Hatfield, J. An Empirical Examination of the Relationship Between Corporate Social Responsibility and Profitability. Acad. Manag. J. 1985, 28, 446-463.

33. McGuire, J.; Sundgren, A.; Schneeweis, T. Corporate Social Responsibility and Firm Financial Performance. Acad. Manag. J. 1988, 31, 854-872.

34. Margolis, J.D.; Walsh, J.P. Misery Loves Companies: Rethinking Social Initiatives by Business. Adm. Sci. Q. 2003, 38, 268-305. [CrossRef]

35. Xueming, L.; Bhattacharya, C.B. Corporate Social Responsibility, Customer satisfaction, and Market value. J. Mark. 2006, 70, 1-18.

36. Battaglia, M.; Testa, F.; Bianchi, L.; Irlando, F.; Frey, M. Corporate Social Responsibility and Competitiveness within SMEs of the Fashion Industry: Evidence from Italy and France. Sustainability 2014, 6, 872-893. [CrossRef]

37. Coles, T.; Fenclova, E.; Dinan, C. Tourism and corporate social responsibility: A critical review and research agenda. Tour. Manag. Perspect. 2013, 6, 122-141. [CrossRef]

38. Popa, M. Statistici Multivariate Aplicate in Psihologie; Ed. Polirom: Iasi, Romania, 2010. 
39. Tabachnick, B.G.; Fidell, L.S. Using Multivariate Statistics, 3th ed.; Harper Collins: New York, NY, SUA, 1996.

40. Labar, A.V. SPSS Pentru Stiintele Educatiei; Ed. Polirom: Iasi, Romania, 2008.

41. Critical Values for the Durbin-Watson Test: 5\% Significance Level. 2016. Available online: http://web. stanford.edu/ clint/bench/dw05b.htm (accessed on 15 June 2016).

42. Mithas, S.; Tafti, A.R.; Bardhan, I.; Goh, J.M. Information Technology and Firm Profitability: Mechanisms and Empirical Evidence. MIS Q. 2012, 36, 205-224.

43. Waddock, S.A.; Graves, S.B. The corporate social performance-financial performance link. Strateg. Manag. J. 1997, 18, 303-319. [CrossRef]

44. Siminica, M.; Sichigea, M. Corporate Social Responsibility as a Voluntary Initiative but a Mandatory Non-financial Reporting Link Between the Social and Financial Performance of Romanian Companies. In Current Issues in Corporate Social Responsibility. CSR, Sustainability, Ethics \& Governance; Idowu, S., Sitnikov, C., Simion, D., Bocean, C., Eds.; Springer: Cham, Switzerland, 2018; pp. 77-96; ISBN 978-3-319-70449-4. [CrossRef]

45. Albuquerque, R.; Durnev, A.; Koskinen, Y. Corporate Social Responsibility and Firm Risk: Theory and Empirical Evidence; Working Paper; Boston University: Boston, MA, USA, 2015.

46. Zhang, L. The value premium. J. Finance 2005, 60, 67-103. [CrossRef]

47. Nguyen, P.-A.; Kecskés, A.; Mansi, S. Does Corporate Social Responsibility Create Shareholder Value? The Importance of Long-Term Investors. J. Bank. Financ. 2017, in press. [CrossRef]

48. Commission of the European Communities, Promoting a European Framework for Corporate Social Responsibility. EU Green Paper. 2001. Available online: www.europa.eu (accessed on 10 May 2018).

49. Visser, W. Corporate Social Responsibility in Developing Countries. In The Oxford Handbook of Corporate Social Responsibility; Crane, A., McWilliams, A., Matten, D., Moon, J., Siegel, D., Eds.; Oxford University Press: Oxford, UK, 2008; pp. 473-479; ISBN 9780199211593.

50. Chow-Chua, C.; Goh, M.; Wan, T.B. Does ISO 9000 certification improve business performance? Int. J. Qual. Reliab. Manag. 2003, 20, 936-953. [CrossRef]

51. Heras, I.; Dick, G.P.M.; Casadesus, M. ISO 9000 registration's impact on sales and profitability: A longitudinal analysis of performance before and after accreditation. Int. J. Qual. Reliab. Manag. 2002, 19, 774-791. [CrossRef]

52. Garay, L.; Font, X. Doing good to do well? Corporate social responsibility reasons, practices and impacts in small and medium accommodation enterprises. Int. J. Hosp. Manag. 2012, 31, 329-337. [CrossRef]

53. Lee, S.; Park, S.-Y. Do socially responsible activities help hotels and casinos achieve their financial goals? Int. J. Hosp. Manag. 2009, 28, 105-112. [CrossRef]

54. Kasim, A. The need for business environmental and social responsibility in the tourism industry. Int. J. Hosp. Tour. Adm. 2006, 7, 1-22. [CrossRef]

55. Frey, N.; George, R. Responsible tourism management: The missing link between business owners' attitude and behavior in the Cape Town tourism industry. Tour. Manag. 2010, 31, 621-628. [CrossRef] 